\title{
PERANCANGAN APLIKASI PARKING SYSTEM PADA GAJAH MADA FOOD STREET MENGGUNAKAN JAVA NETBEANS
}

\author{
Rahman Salahuddin', V.H. Valentino ${ }^{2}$, Riko $^{3}$ \\ 1,2,3 Informatika, Fakultas Teknik dan Ilmu Komputer, Universitas Indraprasta PGRI \\ Jalan Raya Tengah No 80, Kelurahan Gedong, Pasar Rebo, Jakarta Timur \\ rahmansalahuddin8@gmail.com, ${ }^{2}$ V.h.valentino.na70@gmail.com, ${ }^{3}$ rikobidik@ gmail.com
}

\begin{abstract}
ABSTRAK
Gajah Mada Food Street saat ini masih menggunakan sistem parkir manual yaitu menggunakan tiket dengan menuliskan nomor polisi kendaraan. Sistem tiket yang ditulis secara manual sangat rentan untuk terjadinya kesalahan dalam penulisan. Hal tersebut mengakibatkan penulisan ulang oleh petugas sehingga waktu pelayanan pun menjadi lebih lama. Tujuan dalam penelitian ini adalah menganalisis sistem perparkiran yang sedang berjalan di Gajah Mada Food Street serta merancang sistem yang baru untuk memudahkan petugas dalam pemberian tiket parkir. Metode penelitian yang digunakan dalam sistem informasi ini adalah metode Grounded Research yaitu metodologi penelitian kualitatif yang menekankan penemuan teori dari data observasi empirik di lapangan dengan metoda induktif menemukan teori dari sejumlah data. Untuk mengembangkan sistem ini dilakukan dengan permodelan waterfall menggunakan Java Netbeans. Hasil akhir penelitian ini adalah aplikasi parking system berbasis desktop untuk mendukung kinerja petugas parkir agar lebih efisien dalam pendataan parkir dan memberikan kenyamanan bagi pelanggan.
\end{abstract}

Kata Kunci: Sistem parkir, Kendaraan, Java Netbeans

\begin{abstract}
Gajah Mada Food Street currently still uses a manual parking system, namely using a ticket by writing down the vehicle's police number. The ticket system that is written manually is very susceptible to errors in writing. This resulted in rewriting by the officer so that the service time became longer. The purpose of this study is to analyze the parking system that is currently running at Gajah Mada Food Street and to design a new system to make it easier for officers to provide parking tickets. The research method used in this information system is the Grounded Research method, which is a qualitative research methodology that emphasizes the discovery of theories from empirical observation data in the field with the inductive method of finding theories from a number of data. To develop this system, it is done by using waterfall modeling using Java Netbeans. The final result of this research is a desktop-based parking system application to support the performance of parking attendants to be more efficient in parking data collection and provide convenience for customers.
\end{abstract}

Key Word: Parking system, Vehicle, Java Netbeans

\section{PENDAHULUAN}

Salah satu fasilitas yang masih menggunakan sistem perparkiran konvensional adalah pintu gerbang utama Gajah Mada Food Street.

"Sistem dapat diartikan sebagai kumpulan atau himpunan dari unsur, kompenen, atau variabel yang terorganisasi, saling berinteraksi, saling tergantung satu sama lain dan terpadu". (Sutabri, 2012)

Informasi adalah proses lebih lanjut dari data yang sudah memiliki nilai tambah.

(Widhiarso \& Riasti, 2013)

Sistem pengelolaan parkir yang diterapkan pada Gajah Mada Food Street menggunakan tiket manual, yaitu dengan penulisan nomor polisi kendaraan pada lembaran kertas. Metode tersebut tentu memiliki banyak kekurangan. Petugas sering kali melakukan kesalahan dalam penulisan. Kesalahan tersebut membuat petugas harus melakukan penulisan ulang sehingga pada jam sibuk terjadi penumpukan antrian kendaraan pengunjung. Oleh karena itu diperlukan perancangan sistem parkir yang baru untuk mengatasi masalh tersebut.

Rumusan Masalah penelitian ini adalah bagaimana cara merancang dan membuat aplikasi parking system pada Gajah Mada Food Street yang mencakup sistem pengolahan data karyawan, pencetakan tiket, data transaksi, dan laporan menggunakan Java Netbeans.

Tujuan penelitian ini adalah membangun aplikasi sistem parkir terkomputerisasi yang dapat membantu pengolahan data parkir dan membuat laporan pendapatan parkir. Manfaat 
hasil penelitian dalam masyarakat diharapkan dapat menjadi tambahan atau masukan bahan referensi untuk penelitian selanjutnya dan juga dapat membantu Gajah Mada Food Street mengenai pentingnya aplikasi parking system dalam mengelola perparkiran.

\section{METODE PENELITIAN}

Penelitian ini menggunakan metode grounded research yaitu suatu metode penelitian yang mendasarkan diri kepada fakta dan menggunakan analisa perbandingan bertujuan untuk mengadakan generalisasi empiris, menetapkan konsep-konsep, membuktikan teori dan mengembangkan teori dimana pengumpulan data dan analisa data berjalan pada waktu yang bersamaan. (Nasution, 2018).

1. Observasi

Penulis melakukan penelitian dengan mengamati secara langsung sistem parkir yang sedang berjalan pada Gajah Mada Food Street.

2. Wawancara

Pengumpulan informasi dengan mengajukan sejumlah pertanyaan secara lisan dan dijawab secara lisan. Wawancara dilakukan dengan pihak terkait untuk mengetahui lebih dalam tentang kebutuhan dari sistem parkir yang akan dirancang.

(Kustian, 2019)

3. Studi Kepustakaan

Penulis mengumpulkan data-data dari buku serta laporan lainnya berkaitan dengan penelitian.

(Rusdi et al., 2019)

System Development Life Cycle atau yang disebut dengan istilah SDLC adalah metodologi yang biasa digunakan untuk mengembangkan suatu sistem informasi.

(Susanto \& Dara, 2016)

Model yang digunakan dalam pengembangan sistem ini adalah dengan waterfall model. "Model air terjun (waterfall) menyediakan pendekatan alur hidup perangkat lunak secara sekuensial atau terurut dimulai dari analisis, desain, pengodean, pengujian, dan tahap pendukung (support)". (A.S \& Shalahuddin, 2016)

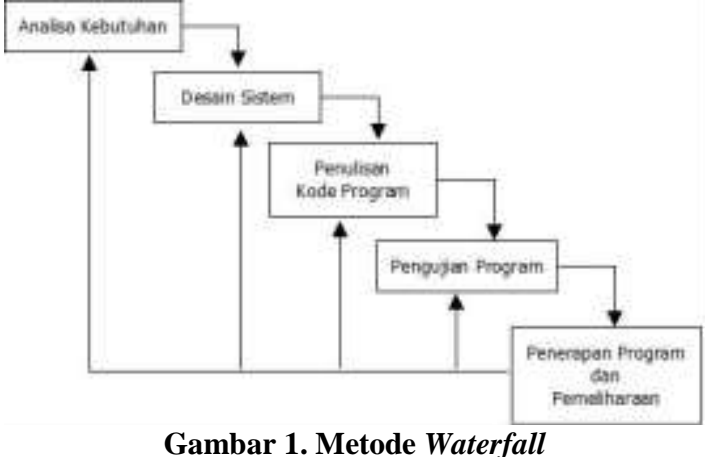

Berikut adalah penjelasan dari tahapan dalam metode Waterfall:

1. Analisa Kebutuhan (Analisys)

Mengumpulkan data dengan lengkap kemudian menganalisis permasalahan yang dihadapi dan menetapkan kebutuhan perangkat untuk membuat desain yang sesuai.

2. Desain Sistem

Setelah analisa selesai dikumpulkan maka ditranslasikan menjadi desain program kemudian diimplementasikan menjadi program pada tahapan selanjutnya.

3. Penulisan Program (Coding)

Desain diterjemahkan menjadi bahasa pemrograman java.

4. Pengujian Program (Testing)

Kegiatan pengetesan program untuk meminimalisir terjadinya kesalahan dan juga memastikan program berjalan dengan baik.

5. Penerapan dan Pemeliharaan

Mengoperasikan program pada tempat sebenarnya serta pemeliharaan program agar dapat terus berjalan tanpa kendala.

(Aji \& Rudianto, 2020)

\section{HASIL DAN PEMBAHASAN}

Hasil dari penelitian pada Gajah Mada Food Street, akan dirancang sebuah aplikasi yang memudahkan dalam pengolahan data parkir serta pembuatan laporan. Dikarenakan pengolahan data yang berjalan saat ini masih menggunakan metode manual yang tidak terkomputerisasi. Dengan dirancangnya aplikasi ini diharapkan mampu membantu kinerja petugas dalam mengatasi permasalahan yang ada saat ini.

UML (Unified Modeling Language)

Dengan UML kita bisa membuat model aplikasi dapat berjalan pada perangkat keras, 
sistem operasi dan jaringan, serta menulisnya dalam bahasa pemrograman apapun.

(Oktaviani et al., 2020)

Berikut ini penggambaran tentang Aplikasi Parking System Pada Gajah Mada Food Street Menggunakan Java Netbeans dalam Diagram sebagai berikut :

\section{Use Case Diagram}

Use case diagram merupakan pemodelan untuk kelakuan (behavior) sistem informasi yang akan dibuat. Use case digunakan untuk mengetahui fungsi apa saja yang ada di dalam sistem informasi dan siapa saja yang berhak menggunakan fungsi-fungsi tersebut.

(Hendini, 2016)

Berikut Use Case diagram parking system pada Gajah Mada Food Street:

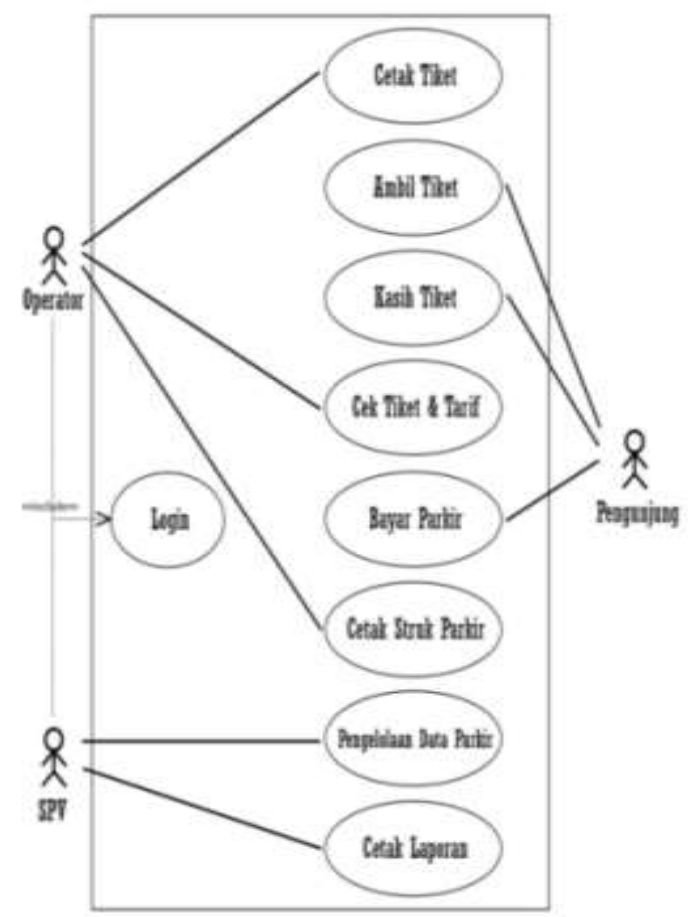

Gambar 2. Use Case Diagram

Alur use case diagram pada gambar diatas merupakan alur keseluruhan dari aplikasi parking system. Aplikasi ini dijalankan oleh tiga aktor, yaitu Operator, Supervisor, dan Pengunjung. Pengunjung sebagai penerima jasa layanan parkir. Operator sebagai petugas yang menjalankan aplikasi parkir untuk pencetakan tiket dan struk parkir. Supervisor bertugas untuk pengelolaan aplikasi parkir seperti mendata operator, mengatur biaya parkir dan mencetak laporan pendapatan parkir.

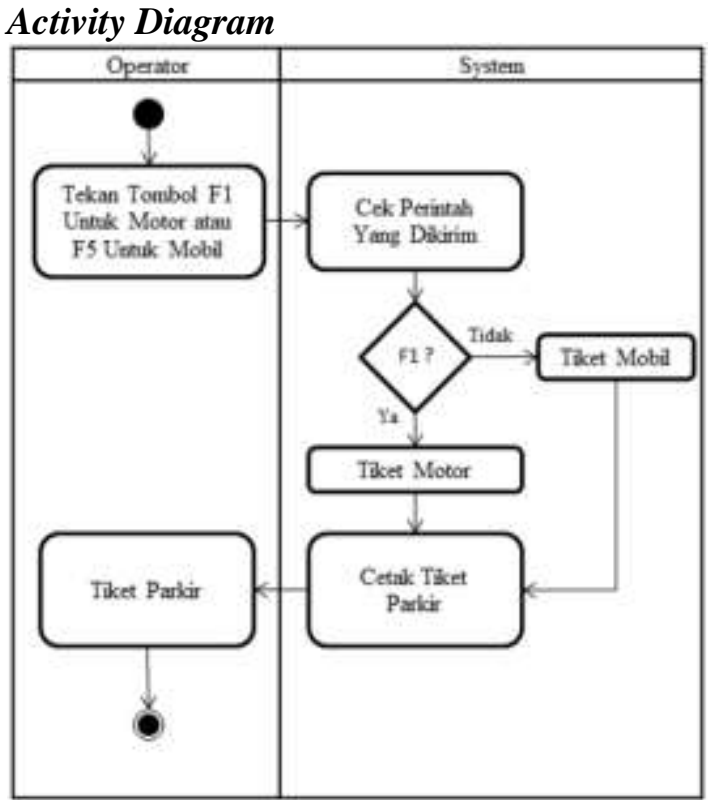

Gambar 3. Activity Diagram

Pada activity diagram diatas petugas parkir dapat mengakses menu cetak tiket parkir. Jika petugas menekan tombol $\mathrm{F} 1$ maka akan mencetak tiket parkir motor, jika menekan F5 maka akan mencetak tiket parkir mobil.

\section{Class Diagram}

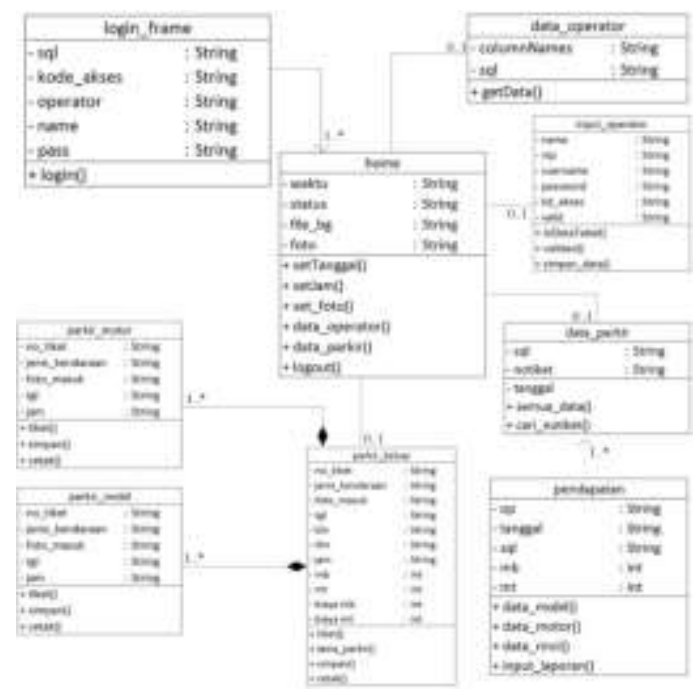

Gambar 4. Class Diagram

Class diagram merupakan penggambaran struktur sistem dari segi pendefinisian kelaskelas yang akan dibuat untuk membangun sebuah sistem. Pada Class diagram di atas adalah bentuk database yang digunakan dalam aplikasi parking system pada Gajah Mada Food Street. 


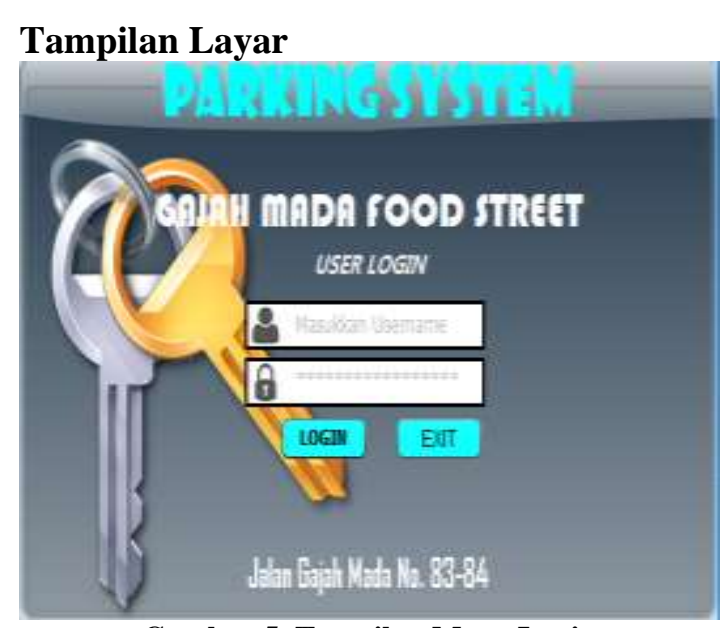

Gambar 5. Tampilan Menu Login

Tampilan menu login adalah tampilan pertama pada saat aplikasi dijalankan. Untuk mengakses masuk ke menu utama, diperlukan username dan password, apabila belum memiliki akun maka harus didaftarkan terlebih dahulu oleh admin atau supervisor. Aplikasi parking system ini memiliki tiga hak akses, yaitu operator, supervisor, dan admin.

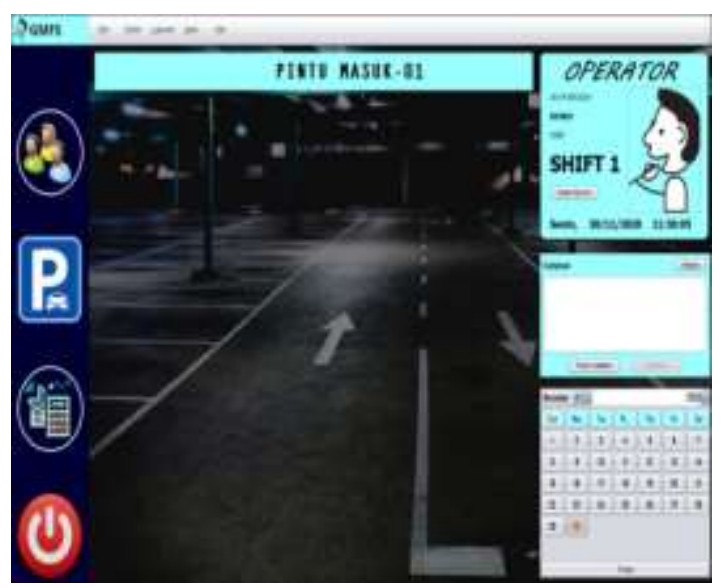

Gambar 6. Tampilan Menu Utama

Pada tampilan menu utama pengguna dapat membuka beberapa menu lainnya yaitu :

Menu File untuk mendaftarkan pengguna baru dan melihat daftar pengguna yang telah diinput ke dalam aplikasi. Menu Parkir untuk mencetak tiket parkir motor dan mobil serta mendata biaya parkir dan mencetak struk parkir. Menu Data untuk melihat data parkir yang telah diinput dan mengubah tarif parkir yang sedang berlaku. Menu Laporan untuk mencetak laporan pendapatan parkir.

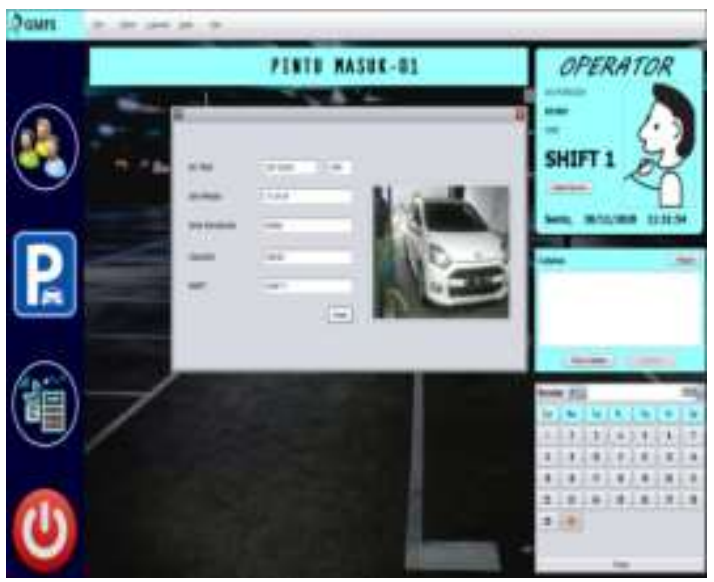

Gambar 7. Tampilan Form Masuk Parkir

Pada tampilan form masuk parkir terdapat data yang secara otomatis terisi sehingga meminimalisir terjadinya kesalahan pendataan. Form ini digunakan untuk mendata setiap ada pengunjung yang datang menggunakan kendaraan dan mencetak tiket parkir.

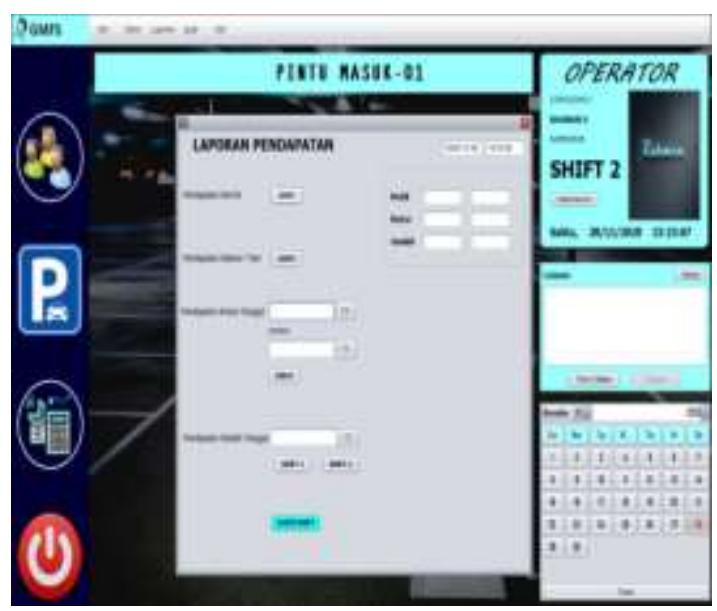

Gambar 8. Tampilan Form Laporan Pendapatan

Pada tampilan form laporan pendapatan terdapat beberapa pilihan untuk mencetak laporan, seperti laporan pendapatan harian, laporan pendapatan mingguan, laporan pendapatan rentang waktu, dan laporan pendapatan per shift. Setelah memilih laporan, form ini akan menampilkan rincian data parkir berupa jumlah kendaraan motor dan mobil lalu memunculkan form laporan baru yang dapat langsung dicetak. Form tersebut hanya bisa diakses oleh supervisor. 


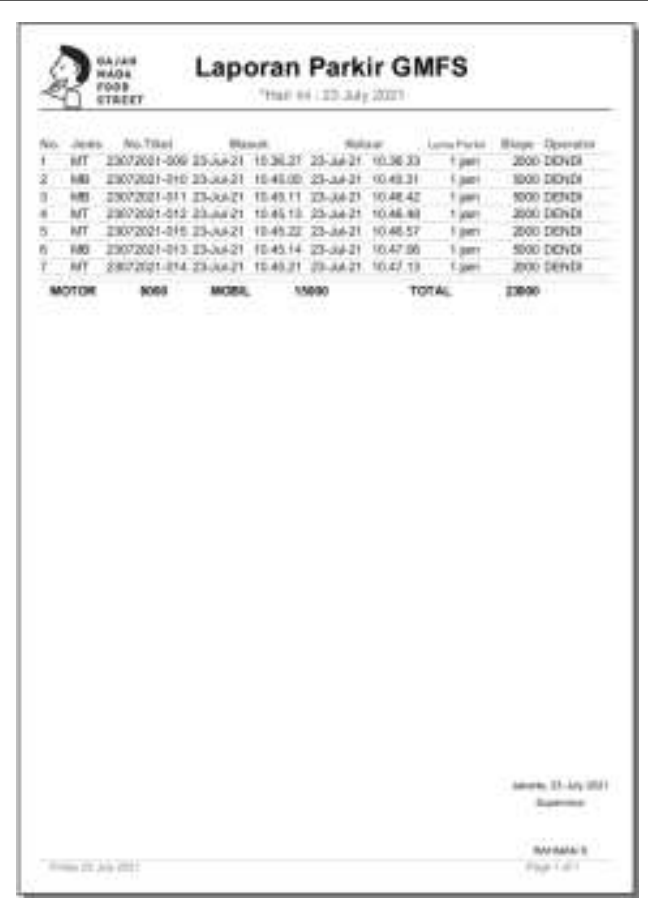

Gambar 9. Tampilan Laporan Pendapatan Harian

Pada tampilan laporan pendapatan harian parkir, berisi data tiket yang telah keluar beserta biaya parkirnya dan juga total pendapatan keseluruhan untuk satu hari.

\section{SIMPULAN DAN SARAN}

Dengan dibangunnya aplikasi parking system ini dapat menjadi solusi untuk memecahkan beberapa masalah yang ada pada Gajah Mada Food Street. Penggunaan sistem parkir yang terkomputerisasi membantu mengurangi kesalahan yang sering terjadi, membantu mempercepat proses perhitungan biaya parkir, dan mempermudah pembuatan laporan parkir.

\section{DAFTAR PUSTAKA}

A.S, R., \& Shalahuddin, M. (2016). Rekayasa Perangkat Lunak Terstruktur dan Berorientasi Objek. Bandung: Informatika. In Jurnal Pilar Nusa Mandiri. Informatika Bandung.

Aji, A. M. B., \& Rudianto, B. (2020). Sistem Informasi Pembayaran Parkir Berbasis Web Dengan Menggunakan Model Waterfall. INTI Nusa Mandiri, 15(1 SEArticles). https://doi.org/10.33480/inti.v15i1.1367

Hendini, A. (2016). Pemodelan Uml Sistem Informasi Monitoring Penjualan Dan Stok Barang. Jurnal Khatulistiwa Informatika, 4(2), 107-116. https://media.neliti.com/media/publicati ons/280381-pemodelan-uml-sisteminformasi-monitorin-4f276586.pdf

Kustian, N. (2019). Penggunaan Model Waterfall dalam Pembuatan Aplikasi Pemesanan Tiket Bus. STRING (Satuan Tulisan Riset Dan Inovasi Teknologi); Vol. 4 No. 1 Agustus 2019. https://journal.lppmunindra.ac.id/index. php/STRING/article/view/3768

Nasution, E. Y. P. (2018). Analisis Terhadap Disposisi Berpikir Kreatif Siswa Pada Pembelajaran Matematika. Edumatika: Jurnal Riset Pendidikan Matematika, 1(1), 44. https://doi.org/10.32939/ejrpm.v1i1.217

Oktaviani, R., Nazwirman, N., Djamaludin, D., \& Windyasari, V. (2020). Aplikasi Sistem Parkir Kendaraan Bermotor Menggunakan Teknologi Radio Frequency Identification (RFID) Di Universitas Islam Syekh Yusuf Tangerang. Jurnal Ilmiah Fakultas Teknik, $\quad l(2 \quad$ SE-Articles). http://ejournal.unis.ac.id/index.php/jimt ek/article/view/1065

Rusdi, I., Mulyani, A., \& Safitri, A. (2019). Rancang Bangun Sistem Informasi Penjualan Pada Pt. Picotel Nusantara Menggunakan Metode Waterfall. Inti Nusa Mandiri, 14(1 SE-Articles). https://ejournal.nusamandiri.ac.id/index .php/inti/article/view/598

Susanto, R., \& Dara, A. A. (2016). Perbandingan Model Waterfall Dan Prototyping Untuk Pengembangan Sistem Informasi. Majalah Ilmiah Unikom, 14(1), 41-46. https://jurnal.unikom.ac.id/jurnal/perba ndingan-model-waterfall.5u

Sutabri, T. (2012). Analisis Sistem Informasi. Yogyakarta: Andi.

Widhiarso, Y., \& Riasti, B. K. (2013). Rancang Bangun Sistem Informasi Nilai Akademik Dan Presensi Siswa Berbasis Sms Gateway Pada Sdn Tulakan III. Indonesian Journal on Networking and Security, 2(4), 1-6. http://ijns.org/journal/index.php/ijns/arti cle/view/191 